\title{
Giuseppe Arcimboldo y la parodia pictónica del lenguaje y su doble. A propósito de los dibujos que integran la revista Ciencias Sociales y Educación n. ${ }^{0}$ 20*
}

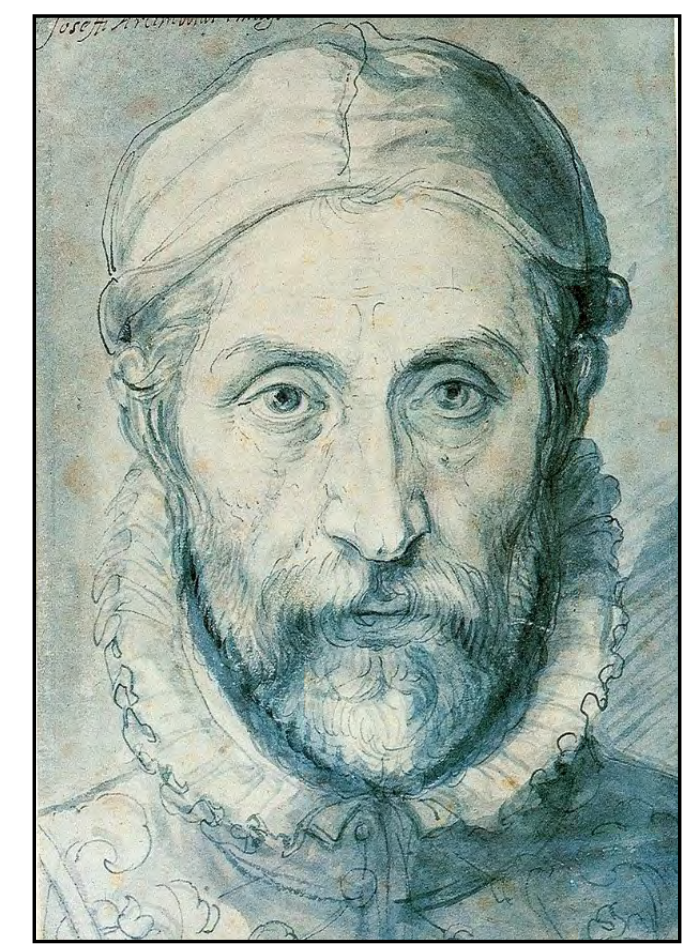

Autorretrato de Giuseppe Arcimboldo (1527-1593)

Fuente: Galería Nacional de Praga:

\section{Hilderman Cardona-Rodas}

Facultad de Ciencias Sociales y Humanas Universidad de Medellín, Medellín, Colombia hcardona@udemedellin.edu.co https://orcid.org/0000-0002-6778-2102

Cómo citar: Cardona-Rodas, H. (2021). Giuseppe Arcimboldo y la parodia pictórica del lenguaje y su doble. A propósito de los dibujos que integran la revista Ciencias Sociales y Educación n. ${ }^{\circ} 20$. Ciencias Sociales y Educación, 10(20), 343-349. https://doi.org/10.22395/csye.v10n20a18

Recibido: 24 de junio de 2021.

Aprobado: 8 de agosto de 2021. 
Seguimos siendo leibnizianos, aunque ya no sean los acordes los queexpresan nuestro mundo o nuestro texto.

Descubrimos nuevas maneras

de plegar como también nuevas envolturas, pero seguimos siendoleibnizianos porque siempre se trata de plegar, desplegar, replegar. (Deleuze, 1989, p. 177)

Giuseppe Arcimboldo (1527-1593), pintor manierista ${ }^{1}$ italiano del siglo XVI, es un juguetón de los efectos ópticos que subliman la polifonía de la imagen. En cada una de sus pinturas se despliegan tales efectos en un doble, o doblez, en tanto operación de plegado como divertimento ante la perplejidad de la imagen entre la metonímia y la metáfora. Como un poeta barroco al estilo de Cyrano de Bergerac (1619-1655), juega con las curiosidades y posibilidades del lenguaje que se despliegan en sinonimias y homonimias. "Su pintura tiene una carga lingüística, su imaginación es claramente poética: no crea signos, los combina, los permuta, los descibre -en eso mismo consiste la tarea del obrero del lenguaje" (Barthes, 2014, p. 8). Este lenguaje remite a la expresividad de un rostro y a la corporeidad en tanto un organismo plástico, esculpido por líneas segmentadas, pliegues vivos, modelo biológico del origami.

Tejido. Textura. Cabellos, piel y boca creados por la fragua topológica de un artísta juguetón que hace de sus obras cuentos de hadas de personajes alegóricos. Cuerpo-gemido-pliegue de ojos que asaltan, despliegue que se dobla en las manos del panadero-pintor Arcimboldo, que amasan la dulce boca inerte ante los fulgores del arte de plegar la imagen. Organismo-flujo plegado que se refleja en obras como Las cuatro estaciones (1563, 1572 y 1573) y Los cuatro elementos (1566 y 1570), en los que se teje un complejo conjunto de segmentaridades que pasan a fundirse con el cuerpo en una especie de teatralidad onírica donde la inconsistencia, la fragilidad y el desgaste son condiciones imprescindibles para una nueva escena, un nuevo escenario, un nuevo guion y nuevos personajes.

"Individuos o grupos estamos hechos de líneas, de líneas de muy diversa naturaleza" (Deleuze y Parnet, 1980, p. 141). Un primer tipo de línea sería de segmentaridad: la familia-la profesión; el trabajo-las vacaciones; la familia-y luego la escuela-y luego la fábrica-y luego el retiro. Cada obra de Arcimboldo

\footnotetext{
El manierismo, como nos recuerda Umberto Eco (2011), remite a una época en el que el artista, inmerso en la inquietud y en la melancolía, "ya no tiende a lo bello como imitación sino a lo expresivo... El manierista tiende a la subjetivación de la visión: mientras que la perspectiva monocular de los renacentistas pretendía reconstruir una escena como si fuera vista por un ojo matemáticamente objetivo, el artista manierista disuelve la estructura del espacio clásico en las visiones pobladas y carentes de un centro destacado de Brueguel, en las figuras distorsionadas y 'astigmáticas' de $\mathrm{El} \mathrm{Greco,} \mathrm{en} \mathrm{los} \mathrm{rostros} \mathrm{inquietos} \mathrm{e} \mathrm{irrealmente} \mathrm{estilizados} \mathrm{de}$ Parmigianino. Existe una preferencia por lo expresivo frente a lo bello, una tendencia a lo extraño, a lo extravagante y a lo deforme, como en las figuras fantásticas de Arcimboldo" (Eco, 2007, p. 169).
} 
está formada por paquetes de líneas de segmentariedades. Otro tipo de líneas serían moleculares, líneas que atraviesan tanto a lo representado por Arcimboldo como a la sociedad que es escenificada en el despliegue de cada obra del artísta manierista.

Heinrich von Kleist (1777-1811) ya sostenía en 1810 que existiría un tipo de líneas que pone en movimiento una fuga en la intensidad de los cuerpos, los cuales bailan al ritmo hipertrofiado del poder significante de la imagen, en el caso de las obras de Arcimboldo. Dice Kleist (2015):

Pero habría otro tipo de líneas, líneas inerciales por los umbrales, irreversibles, no preexistentes: son líneas de gravedad y de celeridad, la línea de fuga y de mayor pendiente, la línea que el punto de gravedad tiene que describir sería muy sencilla, a su entender, y recta en los más de los casos. Cuando fuera curva, la ley de esa curvatura parece, a lo menos, de primer grado, o, a lo más, de segundo; y en este último caso sólo [sic] podría ser elíptica, forma de movimiento enteramente natural a los extremos del cuerpo, por razón de las articulaciones, y cuya ejecución no reclamaría, pues, del maquinista ningún arte especial.

Esa línea, empero, constituía, desde otro aspecto, algo muy misterioso. Era nada menos que el camino del alma del bailarín, y él dudaba que la tal línea pudiera ser hallada de otro modo que trasladándose el propio maquinista al centro de gravedad de la marioneta, o sea, con otra palabra, danzando. (p. 70)

La segmentaridad en la línea de fuga que danza en las obras de Arcimboldo convierte a la pintura en el ejercicio de plagado que se ha venido evocando, pues dota a la pintura de una doble articulación, doblez reflexivo.

Sus cabezas se descomponen, primero, en forma que ya son objetos con nombre, es decir, palabras: la carcasa de pollo, un mazo, la cola de un pescado, legajos de papeles: estos objetos, a su vez, se descomponen en formas que, por sí solas, no significan nada: encontramos así esa doble escala de las palabras y los sonidos. (Barthes, 2014, pp. 13-14)

He aquí la danza en la provocación estética de lo que se ve o la línea de fuga que sugiere Arcimboldo al desdoblar a la imagen produciendo una especie de monstruo estructural que cuestiona la simple representación al hacer de la imagen un campo de interpretación de acontecimientos posibles. Por ello, es posible ver en sus obras ese arte del plegado en la composición que juega con lo aparente de una representación. Pli selon pli (pliegue sobre pliegue), nos recuerda el músico contemporáneo Pierre Boulez (1925-2016) en la producción de acordes. La filosofía y el arte, vistos en tanto topología musical, es una operación de plegado: "tenemos tantas líneas enmarañadas como una mano. Somos tan complicados como una mano" (Deleuze y Parnet 1980, p. 142). 
Las obras de Arcimboldo que fueron seleccionadas para el presente número de la revista proyectan aquel plano de inmanencia del plegado. En ellas, se exponen ante nuestros ojos las comisuras, las fisuras, los pliegues, los torbellinos, los almizcles, las pieles, los velos, los trapos, el tejido flexible geométrico de variaciones figuradas: turbulencias de carne entre lo sólido y lo fluido en trance ante los elementos en combinación. Estas combinaciones posibles en el gesto estético del pintor se movilizan como las escamas de cebolla, alcachofa o feto a la invaginación de complexiones, informaciones, interpretaciones, saberes, en una especie de teoría del conocimiento que teje vertientes, nudos, pliegues. En cada obra es necesario destejer, según Serres (1983), el

advenimiento de una desmología, discurso de los lazos, de los ligamentos, de las ligaduras. Las briznas que se traslapan hacen sombra las unas sobre las otras, y es aceptando esta sombra y este encabalgamiento como el saber crece y se resume. Deseo que se reconozca el valor gnoseológico de la operación de anudar, de la operación de plegar. (pp. 64-65)

Esta operación de plegado es un proceso de implicación:

El conocimiento está replegado sobre sí como un cordaje, como una proteína, o como un tejido, se invagina también y así se vuelve denso, se llena de complexiones, se llena de información, si, va hacia el saber. Va hacia la deflación. La obra es recubrimiento de escamas o de hojas, cebolla o alcachofa, feto, como una sucesión de automorfismos. El análisis escama la cebolla, la destruye, deshace el corazón de su complexión, diluye lo denso, desaprieta. (Serres, 1983, p. 65)

El bibliotecario, óleo sobre lienzo pintado en 1566; Las cuatro estaciones, pintadas entre 1563, 1572 y 1573; Los cuatro elementos, pintados en 1566 y 1570; el retrato de Rodolfo II como Vertumno ${ }^{2}$, pintado en 1591; y Retrato con verduras (El hortelano), elaborado en 1590, ponen en juego aquella hipertrofia del poder del significante que menciona Roland Barthes, la cual opera como evocación metafórica en el plegue de la metonimia y en la reiteración de la alegoría.

Enumerar frutas, melocotones, peras, cerezas, frambuesas, espigas para sugerir el Verano, es una Alusión. Repetir el pez para formar con él aquí una nariz, ahí una boca es una Antanaclasis (repetir una palabra cambiando su significado). Evocar

La obra de Arcimboldo sobre Rodolfo II, emperador del Sacro Imperio Romano quien nació en 1552 y murió en 1612 y tuvo al pintor italiano entre los artistas de su corte desde 1580, representa al monarca como Vertumno (divinidad romana de origen etrusco que simboliza el cambio de la vegetación en el trascurso de las estaciones, esposo de Pomona, divinidad de la fruta, árboles frutales, jardines y huertas). Fue un trabajo que envió Arcimboldo desde Milán a Praga, acompañado de un poema de Gregorio Comanini (1550-1608) que dice:

Mira la manzana, mira el melocotón

como se me ofrecen en ambas mejillas

redondos y llenos de vida

fijate en mis ojos

de color cereza uno

el otro de color de mora.

No te dejes engañar, es mi cara. 
una palabra con la que comparte una misma sonoridad (iQué clara eres, Clara!), es una Paronomasia; evocar una cosa con otra que tiene la misma forma (una nariz por grupa de un conejo), es una paronomasia de imágenes, etc. (Barthes, 2014, p. 16)

François Rabelais (1494-1553) y Arent van Bolten (1573-1633) exploran los lenguajes cómicos en términos de artificios paródicos, es decir, forgeries, que en Arcimboldo tienen toda su plenitud. Cuando se quiere transmitir un mensaje, por ejemplo, la cabeza de un cocinero o de un campesino, el verano, el fuego o el aire, el artista italiano encripta al ocultar y no ocultar al ojo, que solo a partir de un esfuerzo de distanciamiento logra cambiar el nivel de percepción para captar otro mensaje en el sentido global del artificio de lo "verdadero". He aquí la operación de plegamiento o doblez reflexivo de la provocación estética que el artista encripta. "Todo puede acabar significando su contrario... es decir: todo tiene siempre un sentido, se lea como se lea, pero ese sentido no es nunca el mismo" (Barthes, 2014, p. 22). Y esto se reafirma en la argumentación de Gilles Deleuze (1996) sobre el arte del plegamiento, que es la vida misma en acción estética:

Hay pliegues en todas partes: en las rocas, en los ríos, en los bosques, en los organismos, en la cabeza o en el cerebro, en las almas o en el pensamiento, en las llamadas obras plásticas... Pero eso no significa que el pliegue sea un universal. Me parece que fue C. Lévi-Strauss quien señaló la necesidad de distinguir entre dos proposiciones: "sólo difieren las semejanzas", y "sólo las diferencias se parecen". En el primer caso, lo primero es la semejanza entre las dos cosas, y en el otro es la cosa misma la que difiere, y difiere en principio de sí misma. Las líneas rectas se parecen, pero los pliegues varían, difieren. No hay dos cosas que estén plegadas de la misma manera, ni dos rocas, y no hay un pliegue regular en una misma cosa. Por eso, aunque hay pliegues en todas partes, el pliegue no es un universal. Es un 'diferencial', un 'diferenciante'. (pp. 247-248)

De allí que en las dos clases de conceptos, universales y singulares, el concepto de pliegue sea un singular, el cual avanza variando, permutándose, bifurcándose o metamorfoseándose en una cadena significante que tienen su presencia, en tanto plegamiento estético, en los artificios de Arcimboldo que proyectan un territorio de ensoñación e imaginación en la poética de la imagen donde se entrelazan lo mundano, lo místico y lo profano en los pliegues de las experiencias corporales del lenguaje; toda una esfera topológica donde la sensibilidad juega con la metamorfosis de la representación (volver a mirar para contemplar lo encriptado en lo aparente).

Arcimboldo, como Rebelais y van Bolten, es un panadero de la imagen, esculpe la figura, la estira, la dobla y la pliega; cada doblamiento hace del desplazamiento de la mirada un acontecimiento en el estriaje de cartografías diversas, un plegamiento que corporaliza el rizoma en su manifestación encriptada como

Se pueden consultar las reflexiones sobre Arent van Bolten y la comicidad de lo grotesco, lo cual se refleja en la obra de François Rabelais, que aparecen la revista Cardona-Rodas (2021, pp. 405-410). 
mapa de múltiples entradas y salidas en la estética del sentido difuso que lo performativo despliega en la imagen. Todos los cuerpos en su rostridad están en un flujo perpetuo como ríos, principio interno que permite que las partes entren y salgan continuamente. He aquí la mónada leibniziana que moldea y amasa la memoria, y que nosotros en la revista Ciencias Sociales y Educación en su número 20, a diez años de persistencia, hemos querido compartir en la narrativa de la imagen, en la magia del sentido encriptado en sus pliegues.
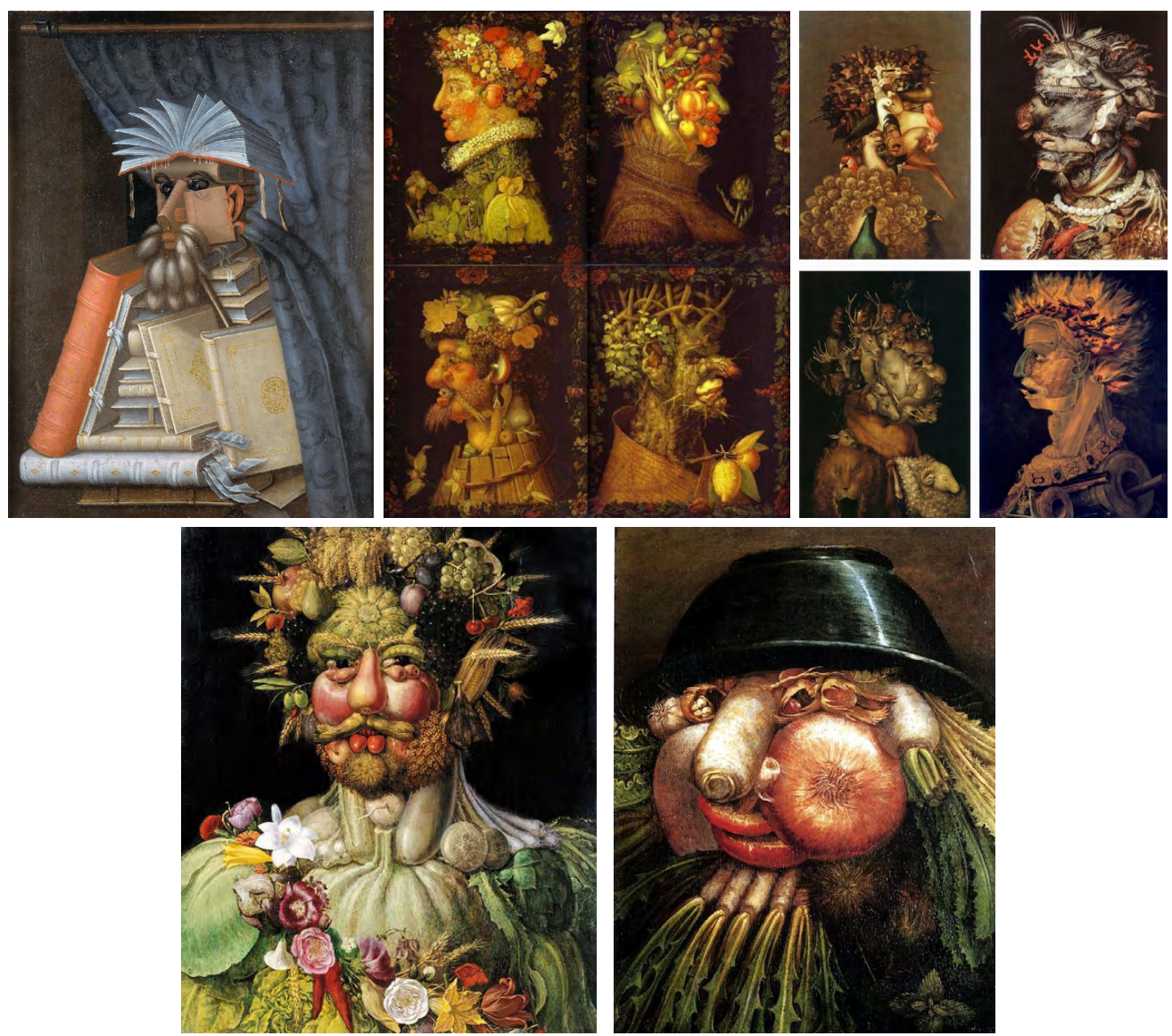

Mosaico de obra de Giuseppe Arcimboldo (1527-1593)

Fuente: revista Ciencias Sociales y Educación n. 20 (julio-diciembre de 2021). 


\section{Referencias}

Barthes, R. (2014). Arcimboldo, retórico y mago. Casimiro.

Deleuze, G. (1996). Conversaciones (Entrevista realizada por Robert Maggiori el 22 de septiembre de 1988 a Gilles Deleuze). Pre-Textos.

Deleuze, G. (1989) El pliegue. Leibniz y el Barroco. Paidós.

Deleuze, G. y Parnet, C. (1980). Diálogos. Pre-Textos.

Eco, U. (2007). Historia de la fealdad. Debolsillo.

Cardona-Rodas, H. (2021). Arent van Bolten y la comicidad de lo grotesco. A propósito de los dibujos que integran la revista Ciencias Sociales y Educación no. 19. Ciencias Sociales y Educación, 10(19), 405-410. https://doi.org/10.22395/csye.v10n19a16

Kleist, v. H. (2015). Sobre el teatro de marionetas. En W. Benjamin, Juguetes (pp. 68-77). Casimiro.

Serres, M. (2001). Rome. Le livre des fondations. Bernard Grasset. Traducción libre de Luis Alfonso Paláu-Castaño. 